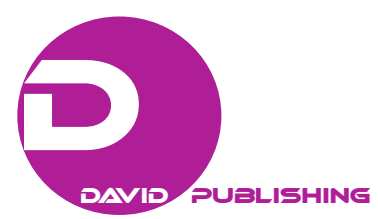

\title{
Estimation of Money Demand Function of South Korea Considering Regime Switching
}

\author{
Byung Woo Kim \\ Korea National University of Transportation, Chungbuk, Korea
}

\begin{abstract}
The stability of money demand function is an important issue in macroeconomic policy implementation. Money demand of Korean economy was estimated. Cointegration test with time dummy variables results show that there is not only long-run equilibrium relationship between money demand and macroeconomic variables, but also structural breaks in this equilibrium relationships. Least squares, state-space, and Marcov switching methods show that there also has been instability (or regime shifts) of parameters in money demand, especially over 1997 crisis and the early 2000s. This fact implies that monetary policy for stabilization might encounter big problems due to change (instability) of money demand.
\end{abstract}

Keywords: money demand function, cointegration, Marcov switching

\section{Introduction}

Korea is suffering from over-liquidity and real estate bubbles, so appropriate implementation of contractor money policy is important than any other period.

The stability of money demand is central issue of monetary policy. If it is unstable accompanying the variation of economic variables, like interest rate, the central bank has no certainty about the effects of monetary expansion on output, especially in recession. Nominal income (or interest rate) is determined by the supply and demand in money. So, deep understanding of money demand in macro-economy is important to the implementation of monetary policy. The motivation of this study is to find whether money demand is really unstable using sophisticated statistical methods.

Fisher (1933) presented quantity theory of money showing that under some assumptions, inflation has one-to-one relationship with the quantity of money.

Monetarists also assert that changing the amount of money can affect nominal output in short-run, due to the stability of velocity of money. This stability issue is also important to the inflation theory and policy. If it is stable, then there is close relationship between the money supply (and money growth) and inflation in the long-run. However, if demand responds sensitively to fluctuations of macroeconomic variables, the effect of money is dissipated into both inflation and output.

Monetarism or new quantity theory of money may be seen as the determination theory of nominal income. It is incomplete in the sense that aggregate supply side is needed to decide how much share is imputed to real

Byung Woo Kim, Ph.D., associate professor, Korea National University of Transportation, Chungbuk, Korea.

Correspondence concerning this article should be addressed to ByungWoo Kim, 72 Daehang No., ChungJu, KOREA $380-702$. E-mail: byungw@cjnu.ac.kr. 
income from the change in aggregate demand.

Beyer (1994) examined the structural change in money demand in Germany due to the 1990 reunification. He concluded that despite dramatic change of 1990 in German economy, money demand seemed not to have structural change. He compared his previous results with new results with the addition of sample period including 1990 reunification of Germany. He considered (weak, strong, and super) erogeneity, parameter stability, non-stationarity, cointergration, dummy variables, error correction (EC), stepwise simplified and reparameterized LS, steady state growth path of real money stock, seasonality of data, encompassing tests, and the applicability of P-star for M3 in German money demand side.

Lutkepohl, Terasvirta, and Wolters (1999), however, found that extending sample period including monetary unification of 1990 revealed substantial instability of German money demand.

Sarno (1999) considered Italian money demand and added the concept of adjustment cost and non-linear (cointegration) dynamics. Fleissig (1998) used the dynamic Laurent form for money demand. Bae and de Jong (2007) also used non-linear cointegration for estimation of money demand. ${ }^{1}$ The dependency only on linear specification may be new main shortcut of study.

For the case of South Korea, several authors have contributed to this area in empirical analyses.

In 1998, Bank of Korea (BOK) adopted inflation targeting and used the short-run interest rate as operating target. But, author should distinguish the differences between monetary targeting and inflation targeting. This classification comes from the categories of implementation system of monetary policy. The choice of nominal anchor leads to the difference between monetary and inflation targeting. This empirical study supports BOK's change in policy implementation from M-based into R-based inflation targeting, since money demand is no longer stable.

Michell (2009) analyzed the tight monetary policy in 1979 of South Korea. Kim (2006) showed that velocity of Korean money has decreased and been unstable. He compared the predictive power for inflation using P-star-model and augmented Phillips curve. This analysis is extended in this study considering Beyer's EC method (1994).

In principle, the instability of money demand means that the Marshall's $k$ is responsive(variable) to (the function of) the interest rate, but this paper considers the parameter instability in the regression equation of money demand on the interest rate in the sense of the second kind of instability.

This paper consists of the following sections. In section 2, ordinary LS for testing stability of money demand was used. In section 3, it considers the non-stationarity of variables and uses cointegration method with structural dummy variables. In addition, it investigates Switching model for seeing structural breaks in money demand. In section 4, it gives some conclusions.

\section{Econometric Model: Linear Regression}

The development of money demand theory in macro-economy originated in quantity theory. But, Keynes' speculative demand concept revolutionized the academic and financial communities. The difficulties related with forecast of demand function were from historical events like oil shocks, monetary targeting in 1970s, and deregulations in financial market in 1980s.

\footnotetext{
1 They applied similar type of error correction mechanism of Sarno (1999). This is different from standard linear EC coefficient of Engle-Granger.
} 
On the theoretical side, dynamic inconsistency of optimal policy theory contributed to the change of monetary policy implementation and the instability of money market.

In part 2, mainly linear regression method is used for estimating money demand. In noting the differences among the cointegration analyses in Part 3, author should be careful in interpreting the results. This paper depends on the concept that in the case of the existence of cointegration, the ordinary least squares (OLS) estimator is "superconsistent". It means that estimator converges more fastly to true parameter when increasing the number of samples. Using OLS is justified when there is cointegration relationship.

The relationships between OLS and state space model are in the argument that in the latter unobserved variable is estimated by maximum likelihood method.

\section{Basic Model}

The (real) money demand (M/P) is expressed by the function of real income $Y$, real interest rate $r$, the inflation rate $\pi$, and the price level. The main reason why this paper studies money demand to see the relationship between money stock and nominal income is that it examines this issue in the framework of simultaneous equations. If money supply is exogenous, the observations for money and income are the intersections of supply and demand. So, it only needs to know the structure of demand. In analyzing money market and money policy, the difference between short run and long run rate is substantial. The main reason is that central banks only are able to adjust short rate, but the real economy is affected by long-run rate:

$$
\mathrm{M} / \mathrm{P}=L(r+\pi, Y) \text {. }
$$

The platform of econometric model is: ${ }^{2}$

$$
\ln M_{t}-\ln P_{t}=\alpha+\beta_{1} \ln Y_{t}+\beta_{2} R_{t}+\varepsilon_{t}
$$

It can impose a restriction on the coefficient of income. This constraint implies constant elasticity of demand for income (e.g., Friedman's new quantity theory):

$$
\ln M_{t}-\ln P_{t}-\ln Y_{t}=\alpha+\beta_{1} S R_{t}+\beta_{2} L R_{t}+\varepsilon_{t}
$$

It distinguishes long- and short-run rate, because they affect money demand differently.

This paper uses the data of financial institution liquidity $(M)$ as monetary aggregate. It includes $M 2$ and long-term time deposit, reserve of non-banking financial intermediaries (eg. insurance company), etc.. Price level $(P)$ is used by consumer price index (CPI). Also, daily call rate and the interest rate of corporate bond are used as short-run $(S R)$ and long-run $(L R)$ interest rates, respectively. Data come from BOK, and are monthly from 1965 to 2009 of Korea. ${ }^{3}$ This paper uses industrial production index as an income variable $(Y)$ instead of GDP (Gross Domestic Product). But, data frequency available is different over each variable, so this paper uses only available ones hereafter. It uses both OLS and cointegration, and when using cointegration method there is no problem of multicollinearity.

It transforms the level variable into log value denoting by lowercase letters:

$$
M_{t}-P_{t}-Y_{t}=\alpha+\beta_{1} S R_{t}+\beta_{2} L R_{t}+\varepsilon_{t}
$$

The left-hand side (LHS) can be viewed as the inverse of velocity, and Figure 1-6 show that it is unstable across sample periods. To confirm the logic of traditional Keynesian view that income velocity of money varies in response to the change of the interest rate, this paper performed causality (erogeneity) test. Instability of

\footnotetext{
2 This paper omits the inflation variable in this analysis as explanatory variables, focusing only on the production and the interest rates.

${ }^{3}$ When mismatched, this paper uses data period only when all variables are totally available.
} 
velocity implies instability of real money demand. Macroeconomists have different views on the stability of velocity. This study may give a little insight on empirical evidence. Velocity is equal to the inverse of Marshall's $k$.

The instability of velocity across sample periods can be seen. Velocity had decreased until 1997 financial crisis, and after that showed slightly upward trend.

Instability in money demand may mean two different facts. First, velocity is the function of the interest rate. Second, the function may have structural change. It can be found that velocity has decreased until recently and the volatility of velocity itself is high. This paper investigates these two implications and derives appropriate policy implications. Meanwhile, in monetary theory, there is "Goodhart's law", which asserts that monetary aggregates move differently, when government starts to intervene in money market.

The volatility is measured by time-varying standard deviation (or variance) in $\mathrm{ARCH}$ equation for velocity. The relation between OLS is that ARCH relaxes the homoscedasticity assumption in time-series analysis. The presentation for velocity is related with the stability of demand function.

LOG(LF)-LOG(CPI)-LOG(IP)

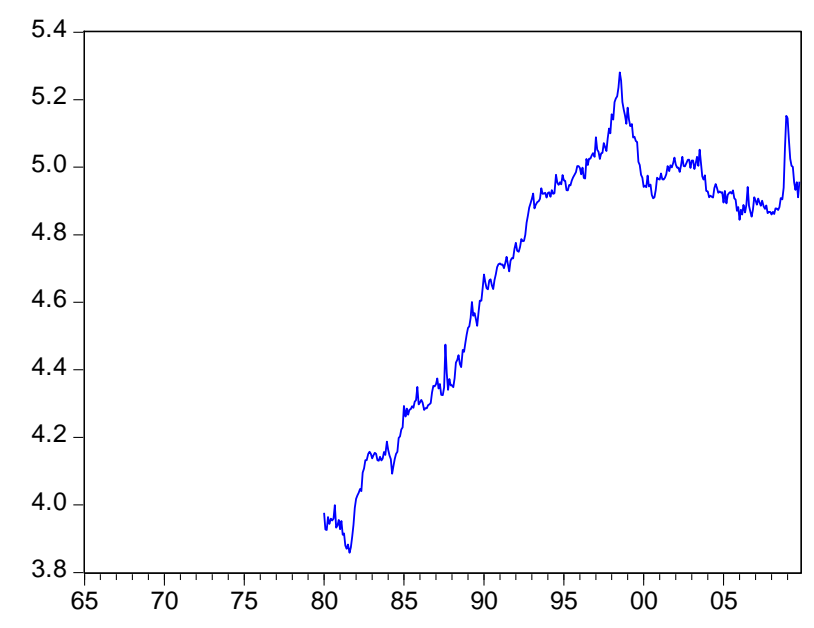

Figure 1. Velocity of income.

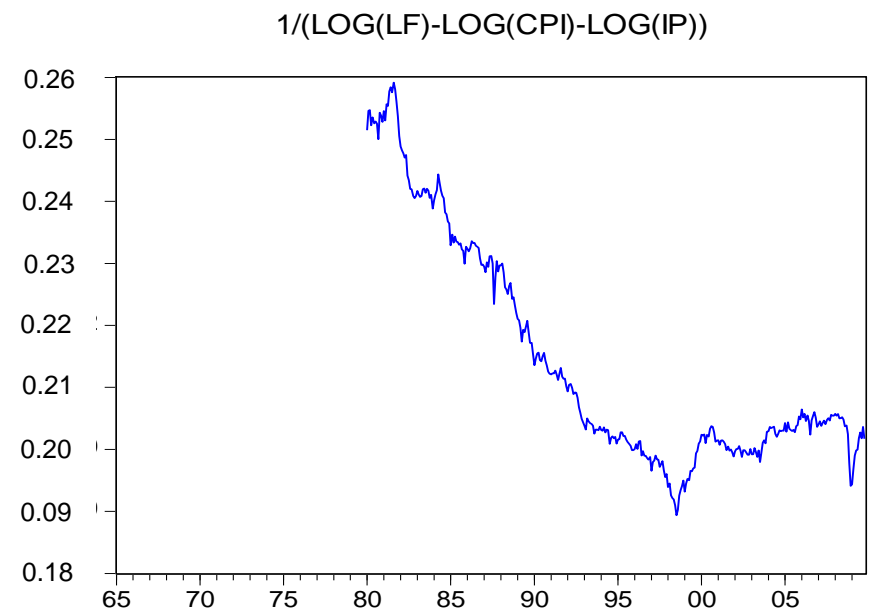

Figure 2. Inverse ofvolatilityof velocity of income. 


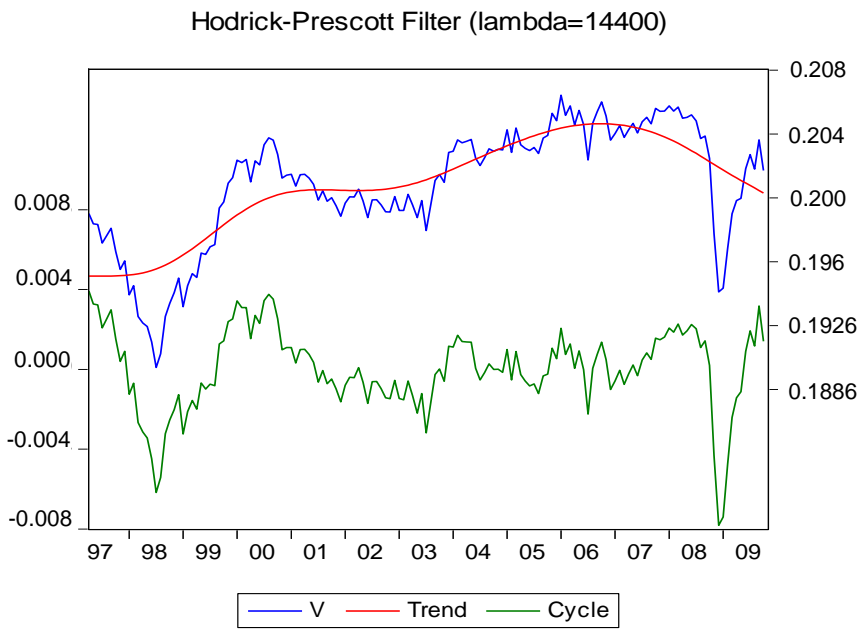

Figure 3. Velocity of income from 1997 to 2000 . $^{4}$

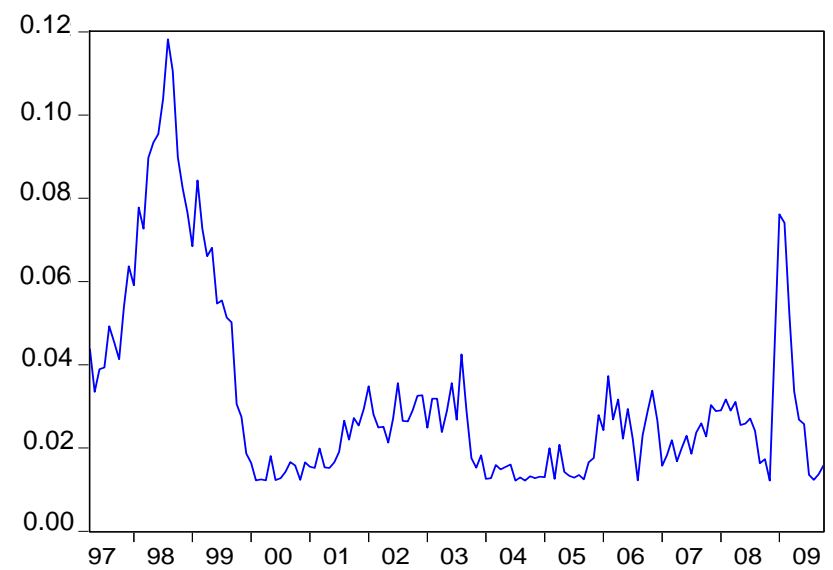

- Conditional standard deviation

Figure 4. Conditional SD estimated from $\mathrm{ARCH}$ in velocity equation.

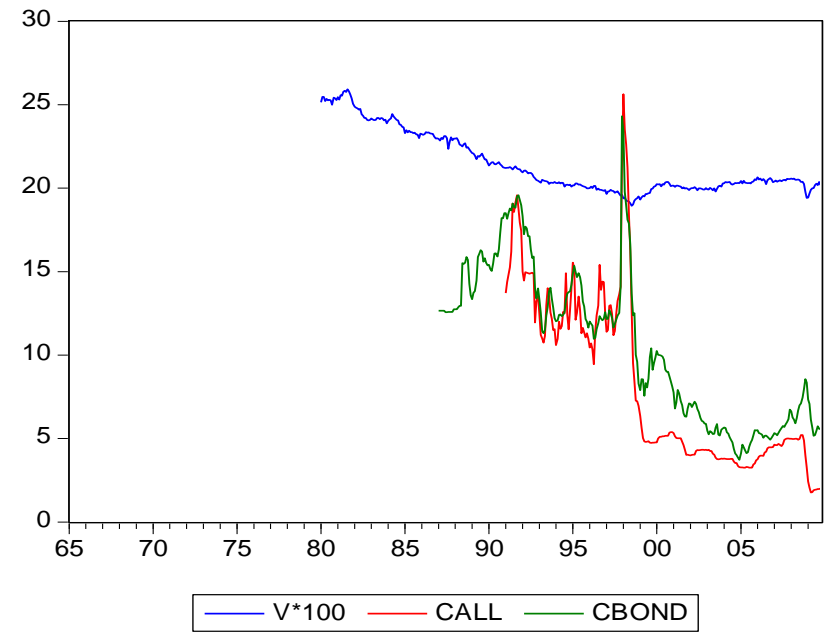

Figure 5. Velocity and LR, SR interest rates.

\footnotetext{
${ }^{4}$ This filter is used to show trend and cyclicity of velocity.
} 


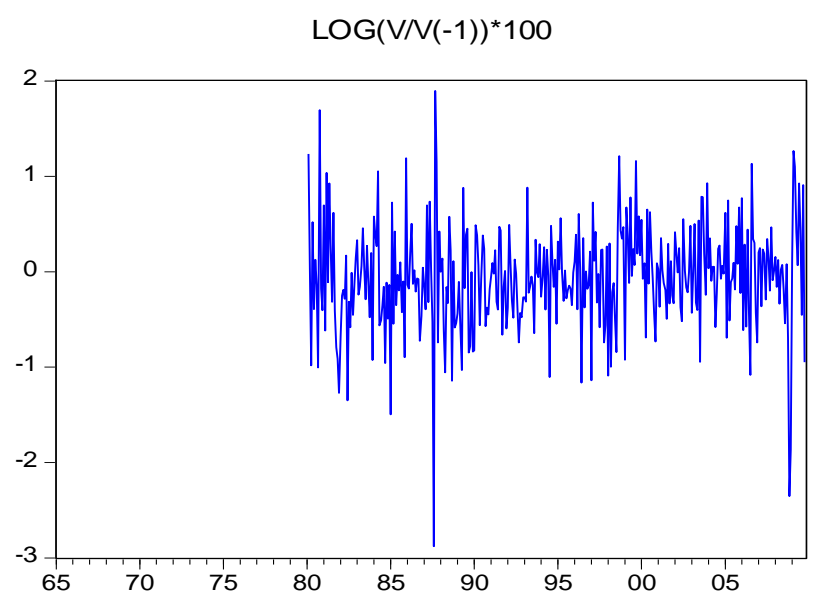

Figure 6. Growth rate of velocity. Source: Kole and Meade (1995).

Table 1

Estimation of ARCH and Cointegrating Vector

\begin{tabular}{lllll}
\hline & Coefficient & Std. Error & $z$-Statistic & Prob. \\
\hline$C$ & 0.202 & 0.000 & $1,099.105$ & 0.000 \\
$C$ & 0.000 & 0.000 & 6.642 & 0.000 \\
$\operatorname{RESID}(-1)^{\wedge} 2^{5}$ & 0.803 & 0.303 & 2.653 & 0.008 \\
\hline
\end{tabular}

Cointegration test using trace test (trace test statistic is a function of canonical correlation in VAR-vector autoregression — variables or residuals) shows that there are two relationships, and normalized (for velocity) cointegration vector implies that velocity is well explained by the interest rate. But, in contrast to the intuition that velocity is increasing function of the interest rate, the sign of vector is minus. This paper discusses this issue in detail later. Of course, using tau statistics considering OLS residuals is also useful (Table 1).

\section{Causality}

Engle and Hendry (1993) considered the exogeneity of explanatory variable. The interest is for the exogeneity of the interest rate. This paper performed pairwise Granger causality test. Generally, no existence of causality in reverse side and weak exogeneity leads to strong exogeneoty. Test results show exogeneity of the short run (nominal) interest rate variable (CALL) $(F=3.92)$. It should be noted that IP and CPI (output and price level) are measured monthly, but GDP is quarterly in Korea. Statistical package automatically adjusted data frequency. Recent GDP data is measured by chain-weighted rather than traditional Pashe or Laspyres methods.

Hereafter, it uses the following abbreviation: money (LF), price level (CPI), short-run interest rate (CALL), long-run interest rate (CBOND), and output (IP).

It also tests the exogeneity of each RHS variable in unrestricted model. That is, there is no restriction on income variable.

$$
\ln M_{t}-\ln P_{t}=\alpha+\beta_{1} S R_{t}+\beta_{2} L R_{\mathrm{t}}+\beta_{3} \ln Y_{\mathrm{t}}+\varepsilon_{t}
$$

Test results show no exogeneity in the (long run) interest rate variables $(F=2.6$, see Table 2$)$. But, this problem is not considered in unrestricted model seriously in this section.

\footnotetext{
5 In general, the advantage of GARCH over ARCH is that the former needs less parameter to estimate. But, to use it, test for GARCH effect is necessary. In the model, ARCH (1) is tested and has significance.
} 
Table 2

Casality Tests

\begin{tabular}{lll}
\hline Null Hypothesis: & \multirow{2}{*}{ Obs } & $\begin{array}{l}F \text {-Statistic } \\
\text { Prob. }\end{array}$ \\
\hline CALL $\rightarrow$ LOG(LF) - LOG(CPI) - LOG(IP) & \multirow{2}{*}{224} & 3.92 \\
& & $0.0212^{* *}$ \\
LOG $(\mathrm{LF})-$ LOG(CPI) - LOG(IP) $\rightarrow$ CBOND & & 2.60 \\
\end{tabular}

\section{OLS and Parameter Stability}

OLS. To test structural break, firstly the equation (3) is estimated by OLS.

The results are in Table 3. The coefficient for long-run interest rate is estimated negative significantly.

Table 3

OLS for Money Demand (LOG $(L F)-L O G(C P I))$

\begin{tabular}{lcl}
\hline & Coefficient & Prob. \\
\hline$C$ & 5.081 & 0.00 \\
CALL & 0.005 & 0.25 \\
CBOND & -0.009 & $0.08^{*}$ \\
LOG(IP) & 0.981 & $0.00^{* *}$ \\
\hline
\end{tabular}

The relation between the results from OLS and cointegration in the next section is that the former is superconsistent in the case of the existence of cointegration. So, the spurious regression problem (Granger \& Newbold, 1974) is not considered and the examination of this problem is postponed into the next section.

Parameter stability. Recursive residuals. Some stability tests are performed for this OLS estimation model. These stability tests see that whether some structural break in parameters occurred in the sample period. This investigates the second kind of instability, that is, not only $V$ is the function of the interest rate but also its coefficient is not constant across periods. Recursive residuals are one-step ahead forecast error resulting from repetitive prediction. Their advantage over Chow-tests is that each coefficient estimate is re-estimated by recursive method.

All parameter stability tests show that in two sub-period, 1997 crisis and the late 2000s, significant deviations (instability) of parameters are from normal value (except for CUSUM of squares, Figure 7).

This paper uses other recursive LSs: CUSUM of squares, one-step forecast, and $n$-step forecast tests. From Figure 7, it can also be seen instability over 1997 crisis and the late 2000s (Figure 8 and Figure 9).

The CUSUM test is used for stability of regression function. It is based on the recursive residuals. If these recursive residuals deviate from the SE bands, it can be inferred that there is parameter instability. The CUSUM of squares test uses the square of recursive residuals. One-step forecast test shows a plot of recursive residuals, SE, and points whose probability is at or below $15 \% . N$-step forecast test carries out a sequence of Chow forecast test.

It also uses Chow's breakpoint, Quandt-Andrews breakpoint, and Chow's forecast tests. This is the test for equivalence of equations across different samples. In general, $F$-test is used for testing null hypothesis. ${ }^{6}$

Test results show that there was significant breakpoint. Chow's forecast test compares the results for two different models. These facts well contrast with those of Beyer (1998) showing no significant instability in

\footnotetext{
${ }^{6}$ If parameters in two equations are different, error variance will also be different. In this respect, $F$-test assuming equal variance is not valid.
} 
Germany. The main idea of stability tests is the focus on SSE when estimated separately or totally. Each method has its own advantage over the others and has some principle, for example, Quandt test estimated over every sample points the one-shot Chow test (Table 4). The following partition of sample is based on the inference about the change in structure and events according to the Table 4 and Table 5.
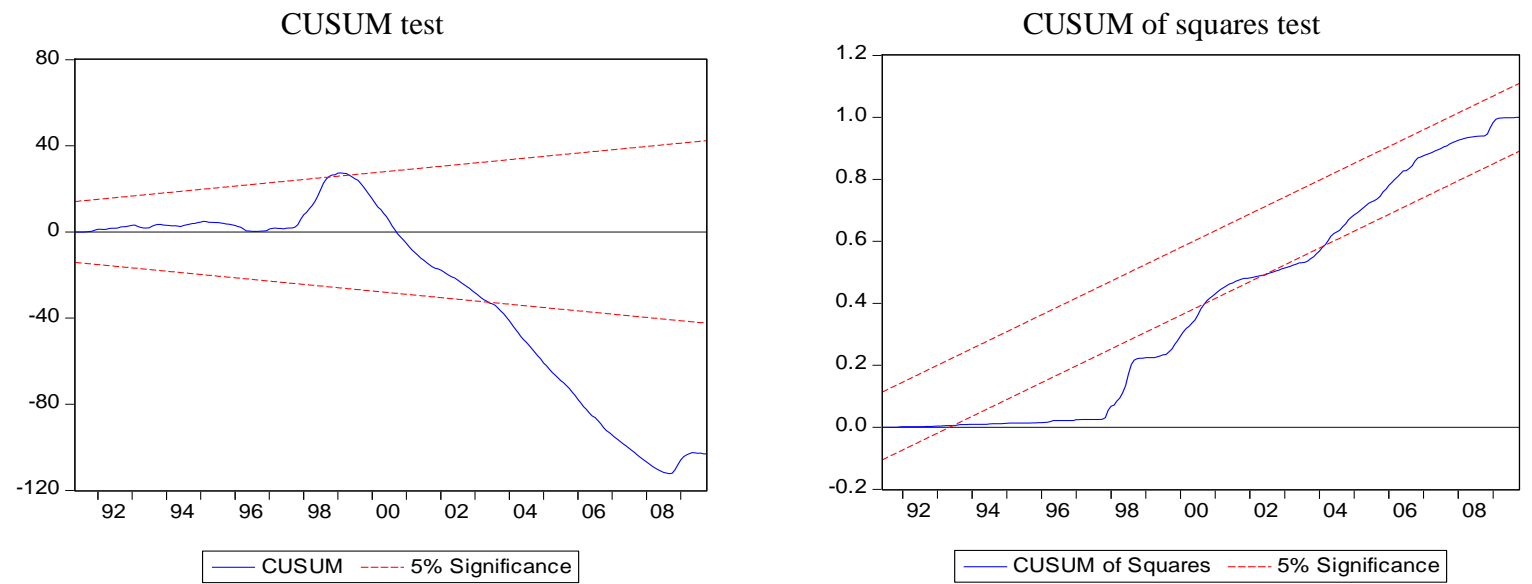

Figure 7. CUSUM test and CUSUM of squares test.
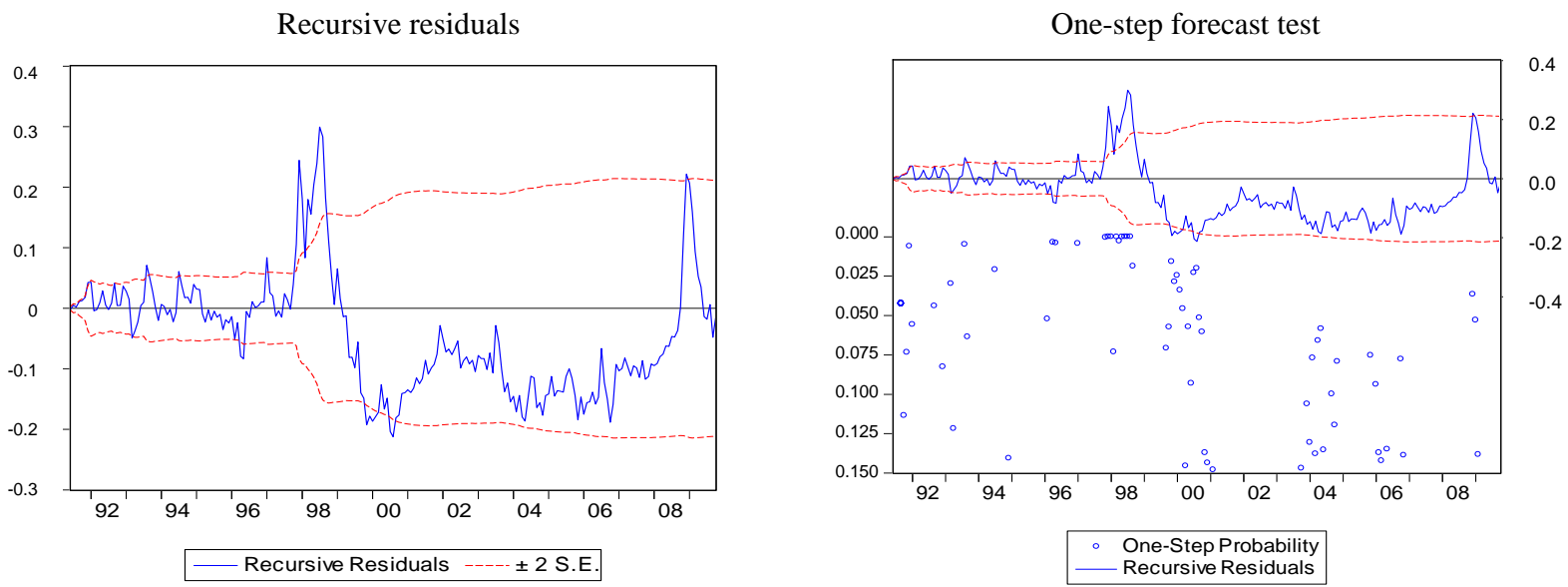

Figure 8. Recursive residuals and one-step forecast test.

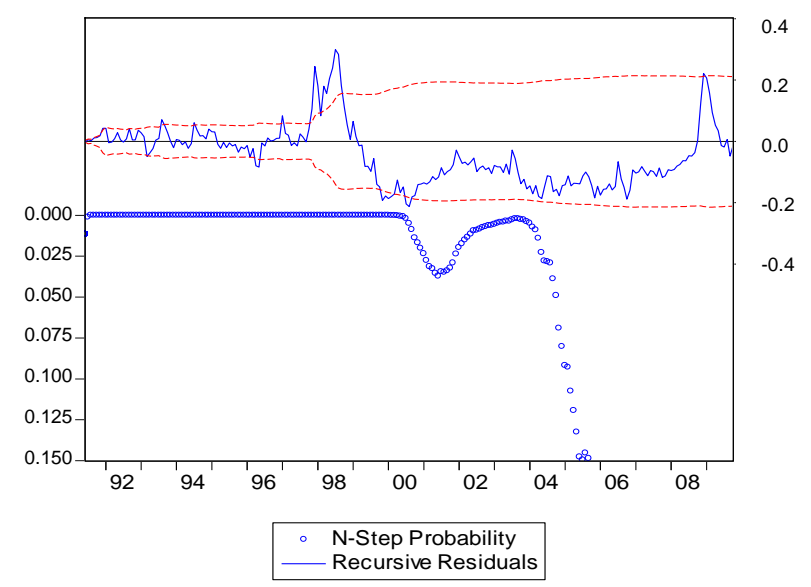

Figure 9. Recursive residuals test for parameter stability. 
Recursive residual is defined in EViews 6.0 as:

$$
w_{t}=(\mathrm{OLS} \text { residual }) /(\text { Forecast error variance })^{(1 / 2)}
$$

Quandt-Andrews break test performs the test of breakpoint between two data points by summing different $k$ statistics at all observations. This examines whether there is a break point between two points. Test results are in Table 5 and it shows rejection of hypothesis of no structural break. In contrasts, Beyer (1898) performed mean Wald (mean $F$ ), exponential Wald, and Hansen's $L_{C}$ tests.

Table 4

Chow Test for Parameter Stability

\begin{tabular}{lc}
\hline Chow Breakpoint Test: 1997 M04 & $0.0000^{* *}$ \\
\hline Prob. F (5.216) & $0.0000^{* *}$ \\
Prob. Chi-square (5) LR & $0.0000^{* *}$ \\
Prob. Chi-square (5) Wald & $0.0000^{* *}$ \\
\hline Chow Forecast Test: Forecast from 1997 M04 to 2009 M10 & $0.0000^{* *}$ \\
\hline Prob. F (151.70) & \\
Prob. Chi-square (151) & $0.0000^{* *}$ \\
\hline Chow Breakpoint Test: 2000 M01 & $0.0000^{* *}$ \\
\hline Prob. F (4.218) & $0.0000^{* *}$ \\
Prob. Chi-square (4) LR & \\
Prob. Chi-square (4) Wald & $0.0000^{* *}$ \\
\hline Chow Forecast Test: Forecast from 2000 M01 to 2009 M10 & $0.0000^{* *}$
\end{tabular}

Table 5

QA Test for Parameter Stability

\begin{tabular}{ll}
\hline Quandt-Andrews unknown breakpoint test & \\
\hline Statistic & Prob. \\
\hline Maximum LR F-statistic (1997 M10) & $0.0000^{* *}$ \\
Exp LR $F$-statistic & $0.0000^{* *}$ \\
Ave LR $F$-statistic & $0.0000^{* *}$ \\
\hline
\end{tabular}

\section{State Space: Time-varying Coefficient}

Finally, this paper estimates state-space model which makes it possible to estimate time-varying coefficient using Kalman-filter. That is, simple state-space model for time-varying coefficient of short interest rate is estimated. State-space model consists of signal equations and state equations. To model the time-varying coefficient, state-space model adopting the famous Kalman filter is used. Kalman filter uses two-step procedure: prediction and updating. Prediction for dependent variable is needed for the updating of parameter estimate. For that, it is necessary to calculate the estimate of parameter based on information up to the past period. Prediction stage gives information for prediction error. This can be used for updating the parameter estimate. In the first stage, an optimal forecast of dependent variable is formed, conditioned on the all available information up to 
the past. For this, an optimal forecast of parameter is needed, conditioned on the all available information up to the past.

$$
\beta_{t \mid t-1} \rightarrow y_{t \mid t-1} \rightarrow \beta_{t \mid t}
$$

This space model is useful for models with unobserved variables like: inflation expectation, natural rate of unemployment, permanent income, and reservation wage. This model estimates (unobserved) time-varying coefficients relaxing time-invariant coefficients assumption in OLS. The coefficient for the short interest rate reveals strong time-varying properties and substantial variation (Table 6).

Estimation results show that in early 1990s, this coefficient (or marginal effect) has negative value, but has increased its value into positive effect (Figure 10). This also seems to affect the stability of money demand. It is worth noting that these estimates are different from those of recursive residuals. In this model, the coefficient shows upward trending, but recursive case mixed. Notwithstanding, it can be concluded that the response of money demand to the change in the interest rate is unstable. Its implication is important in that Bank of Korea performs monetary policy through affecting the (target) call rate (e.g. target federal funds rate in the US) in hope of transmitting the effects into the long-run (nominal) interest rate like corporate bond rate. So, monetary policy focusing on the short rate may be misleading in South Korea, since the marginal effect (the value of coefficient) is unstable. The restriction on the coefficient of CPI is also relaxed. The analysis of random coefficient for long-run rate is omitted.

Table 6

Random Coefficient Model: State-space Model $\log (\mathrm{LF})=C(1)+S V \times$ Call $+C(2) \times \log (\mathrm{CPI})+C(3) \times \log (\mathrm{IP})+C(4) \times \mathrm{CBOND}+$ estate $S V=S V(-1)+u$

\begin{tabular}{lcl}
\hline & Coefficient & Prob. \\
\hline$C(1)$ & 2.879 & $0.0000^{* *}$ \\
$C(2)$ & 2.394 & $0.0000^{* *}$ \\
$C(3)$ & 0.049 & $0.0351^{* *}$ \\
$C(4)$ & -0.001 & 0.5236 \\
$C(5)$ & -11.85 & $0.0000^{* *}$ \\
& Final state & Prob. \\
$S V$ & 0.033 & $0.0000^{* *}$ \\
\hline
\end{tabular}

\section{Marcov Switching}

Based on Marcov switching model, it uses Kalman filter. It is extension of the simple $F$-test of model stability of Chow in 1960. Goldfeld and Quandt (1971) introduced Marcov switching model where the time of switching is endogenous in the model. The common feature with state space model is that they both use Kalman (Hamilton in the case of switching model) filter, but main difference is that switching model incorporates the concept of model (or parameter instability). For simplicity, this section introduces the case of independent switching only considering constant terms. The probability to state 2 (low money demand) is expressed as logistic distribution.

The simple econometric model is:

$$
\begin{aligned}
& \left(\ln M_{t}-\ln P_{t}\right)_{1}=\alpha_{1}+\varepsilon_{1 t}, \varepsilon_{1 t} \sim N\left(0, \sigma_{1}^{2}\right): \text { high money demand; } \\
& \left(\ln M_{t}-\ln P_{\mathrm{t}}\right)_{2}=\alpha_{2}+\varepsilon_{2 t}, \varepsilon_{2 t} \sim N\left(0, \sigma_{2}^{2}\right): \text { low money demand; } \\
& P(s=2)=p \\
& P(s=1)=1-p
\end{aligned}
$$




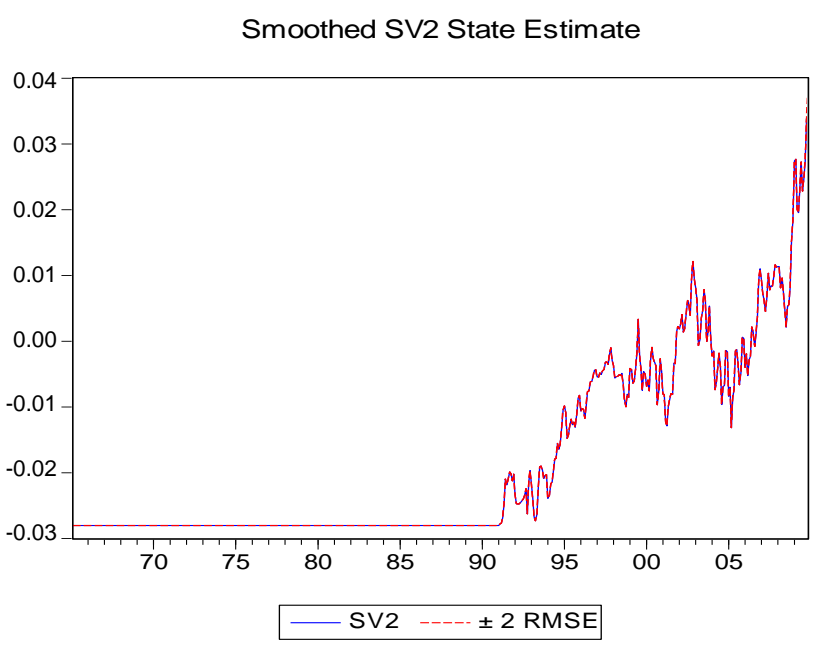

Figure 10. Estimated time-varying coefficient for short run interest rate.

Table 7

Estimation of Marcov (Independent) Switching $\mathrm{Model}^{7}$

\begin{tabular}{llllll}
\hline \multicolumn{2}{l}{ Variable } & Coeff & Std Error & $T$-Stat & Signif \\
\hline 1. & $P$ & 0.426 & 0.065 & 6.506 & $0.000^{* *}$ \\
2. & A10 & 9.375 & 0.049 & 189.3 & $0.000^{* *}$ \\
3. & A20 & 7.724 & 0.158 & 48.704 & $0.000^{* *}$ \\
4. & SIGMA1 & 0.243 & 0.039 & 6.09 & $0.000^{* *}$ \\
5. & SIGMA2 & 0.901 & 0.097 & 9.27 & $0.000^{* *}$ \\
\hline
\end{tabular}

There are high money demand regime and low demand regime. The probability to transition to low regime is 0.426 (Table 7). The implication of this outcome is that the demand equation with just constant reveals regime switching. For simplicity, it only considers independent switching, and more rigorous analysis of (endogenous) Marcov switching considering explanatory variables is needed in future research. The finding is that there is switching in money demand and the probability of it is about $43 \%$.

\section{Long-run Relationship: Cointegration and EC}

As proceeds in this section, all variables in the money demand are non-stationary. This fact may invalidate the analysis of the previous section using OLS. But, if there are cointegration relationships among the variables, it is known that OLS estimators are superconsistent (Davidson \& MacKinnon, 1993). Stock and Watson (1988) argued that cointegrated series have a common trend of some sort. It can be interpreted that linear combination of two cointegrated series is stationary, since this series does not have something that must new present in original non-stationary series. In this cointegration analysis, it adds dummy variables denoting structural breaks in the long-run equilibrium relationship.

From these bases, it can compromise the conintegration analyses with those of LS methods of the previous section.

\section{KPSS Test for Stationarity}

As a first step, unit-root test is performed using Kwitkowski, Phillips, Schumidt, and Shin (1992) (KPSS) method (Table 8), which is recently widely used. This method reverses the strategy of ADF, that is, the null

\footnotetext{
${ }^{7}$ Maximize-Estimation by BFGS.
} 
hypothesis is stationary of variable. ${ }^{8}$ Test results show that all variables are non-stationary, I(1) variables (integrated of order one).

Table 8

KPSS Test

\begin{tabular}{lll}
\hline Null hypothesis: LOG(LF/CPI) is stationary & LM-Stat \\
\hline Kwiatkowski-Phillips-Schmidt-Shin test statistic & & 2.239 \\
Asymptotic critical values*: & $5 \%$ level & 0.4630 \\
\hline
\end{tabular}

\section{Cointegration and EC}

The form of econometric model analyzing long-run relation is in equation (1).

Estimated cointegrating vector (long-run relationship in Table 9) is:

$$
\ln M_{t}-\ln P_{t}=0.87 \ln Y_{t}-0.04 S R_{t}-0.02 L R_{t}
$$

Adding restriction to the coefficient of income reduces is as follows:

$$
\ln M_{t}-\ln P_{t}-\ln Y_{t}=0.32 S R_{t}-0.11 L R_{t}
$$

The estimates for cointegrating vector in equation (2) show that the income velocity of money (the inverse of LHS) is positively related with long-run interest rate. The estimation for cointegration vector assures that a single-equation model for the long run money demand is appropriate and a valid way to proceed (Greene, 2008). In addition, it can use OLS residuals for testing cointegration relationships. By noticing that weather residuals are stationary or non-stationary, this research can determine that whether some series are cointegrated or not.

BOK reported that the elasticity of money demand to income and interest rate is 1.16 and 1.5, respectively. Their results reveal to be large relatively compared to this research. This may come from their using OLS rather than cointegration estimation.

Table 9

\begin{tabular}{|c|c|c|c|c|}
\hline \multicolumn{5}{|c|}{ Restricted cointegrating coefficients (standard error in parentheses) } \\
\hline LOG(LF) & LOG(CPI) & CALL & CBOND & LOG(IP) \\
\hline 1.0 & -1.0 & -0.087 & 0.049 & -0.736 \\
\hline$(0.00000)$ & $(0.00000)$ & $(0.01799)$ & $(0.02218)$ & $(0.14535)$ \\
\hline
\end{tabular}

Cointegration Vector Estimates (1991 M01 to 2009 M12)

Note. Specification 3 (Unrestricted on income).

This paper constructs VEC (vector error correction) model considering short-run money demand change. VEC model has an advent age that it represents not only long-run response (cointegrating part), but also the speed at which it responds to change in equilibrium error (EC part). Lag exclusion Wald test result shows that optimal lags in VEC are 4. VEC is a special case of VAR when the variables are non-stationary (I(1)) and cointegrated.

Estimation results show that the coefficient of cointegrating error is significantly negative. This means that if demand is unusually high relative to cointegrated explanatory variables, demand change may decrease. Exogeneity test results show no significant causality (Table 10).

VAR model is useful in estimating impulse response function and deriving variance decomposition. The former is the function of the parameter coefficients in reduced form system and the latter is the share of the

\footnotetext{
${ }^{8}$ In ADF tests, three types of estimatimg equations are used with constant and trend included or not.
} 
error explained by the variance of specific explanatory variable.

Variance decomposition result shows the contribution of each type of shock to the variance of forecast error. Excluding its own contribution, the shock of long-run interest rate has the largest contribution. That is, its explanation power for money demand is highest. It can be inferred that this share of contribution as "speculative money demand" decreases as the interest rate increases.

The previous results, of having significantly negative coefficient for the long-run interest rate and having large explanatory power in explaining the forecast error variance in money demand, reveal that Korea's money demand is unstable in the first sense of instability, which means that velocity is the function of long-run interest rate.

Estimation for impulse response function shows that the shocks in production have the largest impact on real money demand. Figure 11 shows the equilibrium error in cointegration equation. It shows that before 1997, the error has negative sign and short-run money demand has increased in response to this deviation from long-run relationship, and vice versa. Jumping in error shows that before crisis, error was negative sign and EC was manipulated to the direction of increasing the difference in dependent variable and vice versa.

Table 10

Exogeneity Tests and Cointegration Vector, EC Estimates

\begin{tabular}{ll}
\hline Cointegrating Eq: & Coint Eq1 \\
\hline LOG(LF(-1)) - LOG(CPI(-1)) & 1.000 \\
CALL(-1) & -0.043 \\
CBOND(-1) & 0.017 \\
LOG(IP(-1)) & -0.868 \\
C & -5.322 \\
Error Correction: & $\mathbf{D}(\mathbf{L O G}(\mathbf{L F})-\mathbf{L O G}(\mathbf{C P I}))$ \\
Coint Eq1 & $-0.0144 * *$ \\
\hline
\end{tabular}

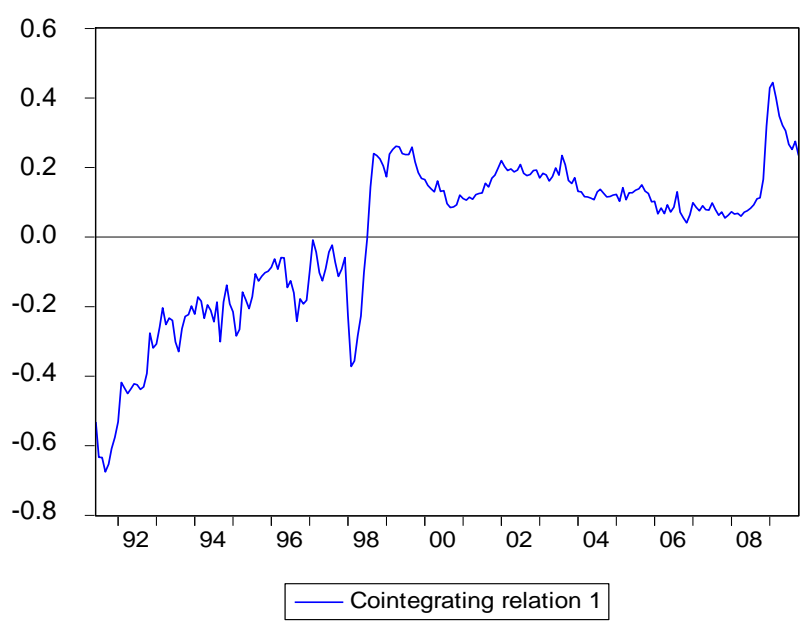

Figure 11. Equilibrium error.

Finally, dummy variables applied to suspected break points are used. It can be noted that first dummy is different from that of the previous section:

Dummy 1: 1 after 2003 M01, 0 otherwise;

Dummy 2: 1 after 1997 M01, 0 otherwise. 
These variables enter into both cointegration part and EC part. Estimation results show that both dummies are significant and reduce both the level and change of money demand than otherwise. Two kinds of dummy are important, since the former implies the change (break) in the cointegration relationships, the latter implies the change in speed at which short run EC occurs. The speed is assumed normally in standard EC model. But, the dummy variable enables to consider the change in speed of EC. EC model with two dummies shows that in the equations of real money demand and production (IP), the EC coefficients are statistically significant (Table 11). The trial incorporating dummy in EC model is important for catching structural breaks in adjusting process responding to the deviation from long- run equilibrium relationship.

Table 11

Cointegration Vector and EC Estimates With Dummy Variables

\begin{tabular}{llllll}
\hline \multicolumn{6}{l}{ Normalized cointegrating coefficients (standard error in parentheses) } \\
\hline LOG(LF) - LOG(CPI) & LOG(IP) & Call & CBOND & $\begin{array}{l}\text { Dummy 2 } \\
\text { (low money demand) }\end{array}$ & $\begin{array}{l}\text { Dummy 1 } \\
\text { (lower money demand change) }\end{array}$ \\
\hline 1.0 & -1.85 & -0.10 & 0.08 & 0.48 & 0.57 \\
& $(0.328)^{* *}$ & $(0.029)^{* *}$ & $(0.034)^{* *}$ & $(0.158)^{* *}$ & $(0.156)^{* *}$ \\
\hline
\end{tabular}

Variance decomposition and impulse response show that long-run rate has the highest explanatory power, and production has the highest effects on money demand, which are similar to those without dummies (Figure 12 and Figure 13).

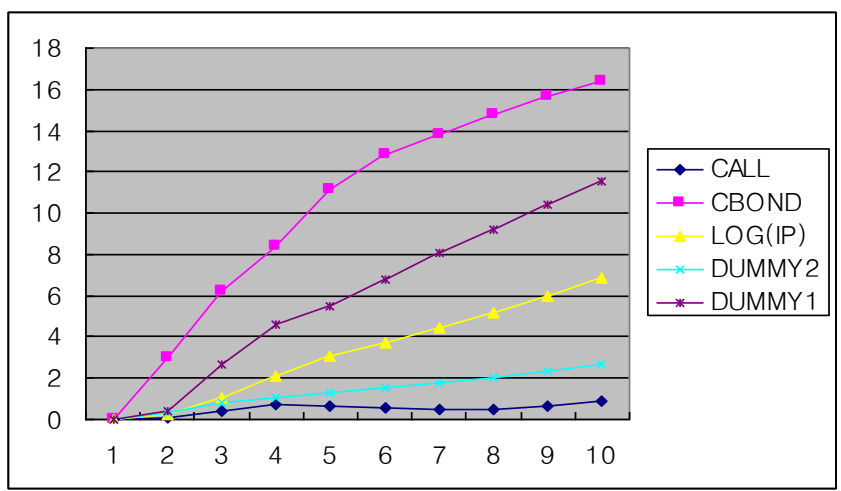

Figure 12. Variance decomposition with two dummies.

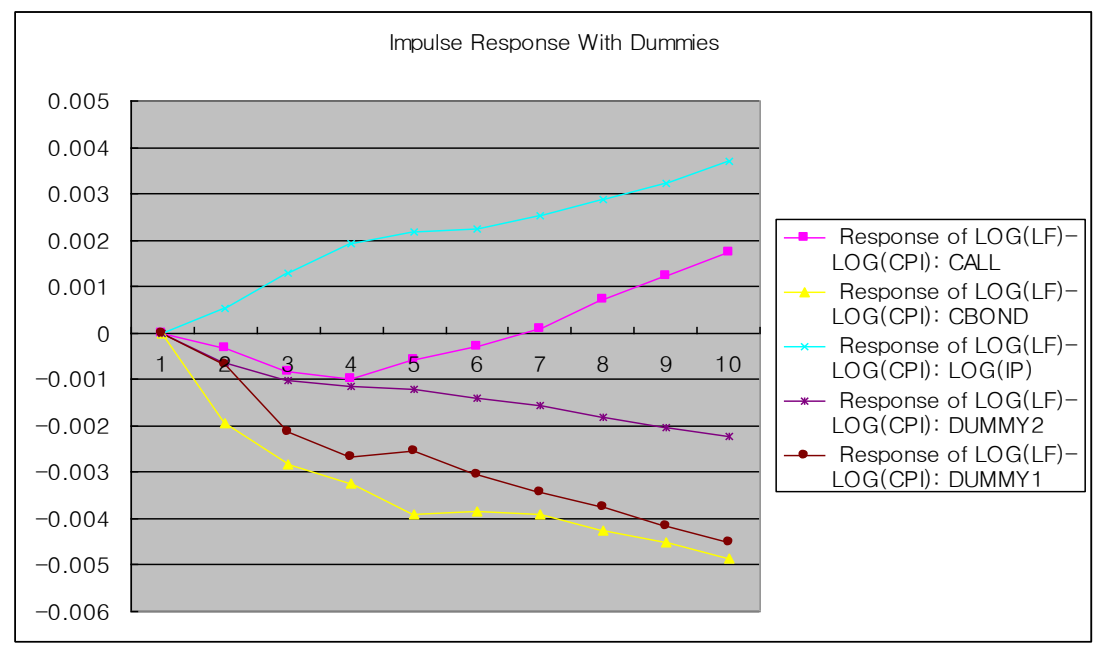

Figure 13. Impulse response with two dummies. 


\section{Monetary Policy Implications}

The implication of the stability in money demand is understood well by using Figure 14. Government (BOK) wants to increase the nominal income by expanding money supply. It hopes to increase nominal income (to B), then, affect real income that is important to resource allocation only if inflation is stable. But, only if money demand $\left(M^{d}\right)$ is stable, it can attain its initial goal. If money demand also moves (to OC, $\mathrm{O}$ is the origin) responding accompanying corresponding change in the interest rate, its policy cannot affect the real economy. Until now, almost all of empirical evidences reveal unstable money demand. So, they imply that monetary policy focusing on changing monetary aggregate may fail due to undesirably unstable money demand.

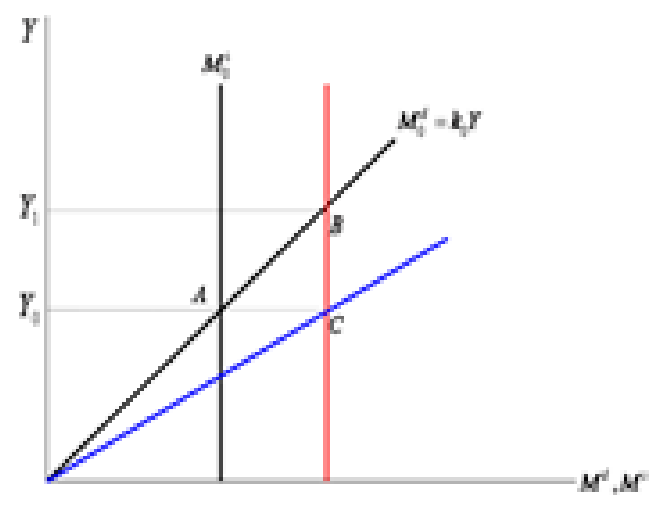

Figure 14. The stability of money demand.

Money demand is expressed as Cambridge equation form:

$$
M^{d}=k(\mathrm{R}) P y=1 / V(R)(P y)
$$

In macroeconomics, the first kind of instability in money demand means that the Marshall's $k$ is the function of (nominal) interest rate, not the fact that the relation between $R$ and $M$ is unstable. This paper needs to recollect the Goodheart's law and Lucas critique. In addition, financial innovation (e.g. innovation of new product of banks) made the money demand respond to the rates of return in diverse assets.

Baumol and Blinder (1994) summarized the determinants of income velocity as follows: firstly, the frequency with which paychecks is received; secondly, the efficiency of payments mechanism likes the use of credit cards; thirdly, the rate of interest; and fourthly, the expected rate of inflation.

Cheong and Kim (2007) presented the factors that prevent economists from forecasting demand accurately. First, they point out aggregate supply shocks like the second oil shock in 1979. Second, many countries adopted monetary targeting and set the amount of monetary aggregate as intermediate target. But, as soon as government controlled the money stock, the behavior of the index of money was changed (Goodhart's law). Third, financial deregulation, liberalization, and globalization have made money demand unstable. Technical progress in financial management, spread of universal banking, financial innovation, and deregulation may be the determinants of the rate of interest in deposit account (Table 12).

From the empirical evidences, the following facts about the causes of unstable money demand can be inferred:

(1) Big depression due to financial crisis (currency + banking) caused large parameter instability in demand, in the view of instability means changing the relationship between $V$ and $L R$;

(2) Government transformed currency market into (managed) floating in Dec. 1997; 
(3) Overnight interbank loan market was liberalized and the call rate (the market outcome) was deregulated;

(4) In the mid and late 1990s, overuse of credit card became social problem in South Korea, and this led to instability (increase) of velocity and liquidity constraints for borrowers with low credit;

(5) In July, 1997, part of the rates of interest in deposit accounts was deregulated. These rates were the costs of banks in financing loan to private firms.

The following shows important change in payments mechanism, financial market, and financial innovation, which seem to have affected the structure in money demand: recession or depression (1997-1998) and deregulation (floating in December, 1997; stock market liberalization in May, 1998; call rate in May, 1999; foreign exchange market reform in April, 2002; and interest rate liberalization in February, 2004)

Table 12

Deregulation for (Determining) Interest Rates (BOK)

\begin{tabular}{llll}
\hline & Lending & Deposit & Bond \\
\hline $\begin{array}{l}\text { Stage 1 } \\
(1991,11)\end{array}$ & Short-run loan & Long run savings deposit \& (CD, RP, and so on) & Corporate bond \\
$\begin{array}{l}\text { Stage 3 } \\
(1994,7 \text { to 1995, 11) }\end{array}$ & Discount rate & Demand deposit & - \\
$\begin{array}{l}\text { Stage 4 } \\
(1997,7)\end{array}$ & - & (7 days to 3 months) savings account & - \\
Current & Subsidy & Demand deposit & \\
\hline
\end{tabular}

\section{Conclusions}

Increasing inflation and relatively low unemployment in multiple objectives of recent period after World War Two made the platform of monetary poly into inflation or interest rate targeting rather than the amount of monetary aggregates. Also, time inconsistency of optimal policy theory (Kydland \& Prescott, 1977; Prescott, 1986) prompted to discard monetary policy from each country's central banks. The model implicitly assumes that monetary policy mainly depends on adjusting monetary aggregates expressed " $M$ " in money demand.

The relation between change in nominal income and monetary aggregate depends on the stability of money demand. The macroeconomic mechanism is presented by Friedman-Phelps's NAIRU model.

In economy of South Korea, Marshall's $k$ has been increased steadily, so this was the motivation of this study. Goldfeld (1973) estimated the US money demand and showed predictive power well. But, his estimation did not have goodness of fit over and after 1970s. This also made researchers to focus on the stability of demand fuction in Korea using more sophisticated econometric methods.

In this paper, it can be found that money demand function was instable over 1965-2009 period and that structural breaks occurred about in 1997 and in 2000.

It can be inferred that the structural break in 1997 came due to Asian crisis and that of 2000 due to financial innovation. This paper's main contribution is that Korea's money demand not only is responsive to the interest rate, but also it shows regime switching or parameter change.

But, more sophisticated analysis is needed and author postpones this for future research.

Recently, macroeconomists deviate from simple Keynesian money demand or quantity theory of money. They developed overlapping generation's model (Samuelson, 1958), cash-in-advance model (Rotemberg, 1987), and money-in-the-utility model (Blanchard \& Fischer, 1989). All these models are based on maximization 
principles of agents and micro-foundation. They may solve the problem of instability of macroeconomic money demand (Romer, 2006).

Finally, financial innovation may have big effect on the stability and this topic is a good example of extension of this study.

\section{Reference}

Bae, Y., \& de Jong, R. M. (2007). Money demand function estimation by nonlinear cointegration. Journal of Applied Econometrics, 22(4), 767-793.

Baumol, W., \& Blinder, A. (1994). Economics (6th ed.). New York: Dryden.

Beyer, A. (1994). Die Geldmenge M3 in Deutschland (University Frankfurt am Mein 33).

Beyer, A. (1998). Modeling money demand in Germany. Journal of Applied Econometrics, 13, 57-76.

Blanchard, O., \& Stanly, F. (1989). Lectures on macroeconomics. Cambridge: The MIT Press.

Cheong, U., \& Kim, Y. (2007). Macroeconomics, YulGok. Retrieved from http://www.yulgokbooks.co.kr/book/

Davidson, R., \& MacKinnon, J. G. (1993). Estimation and inference in econometrics. New York: Oxford University Press.

Engle, R., \& Hendry, D. F. (1993). Testing super exogeneity and invariance. Journal of Applied Econometrics, 56(4), 119-139.

Fisher, I. (1933). The role of macroeconomic factors in growth. Econometrica, 1, 337-357.

Fleissig, A. R. (1998). The dynamic Laurent flexible form and the demand for money. Journal of Applied Econometrics, 12, 687-699.

Goldfeld, S. (1973). The demand for money revisited. Brookings Papers on Economic Activity, 4(3), 577-646.

Goldfeld, S. M., \& Quandt, R. E. (1971). Nonlinear methods in econometrics. Amsterdam: North Hollad.

Granger, C., \& Newbold, P. (1974). Spurious regressions in econometrics. Journal of Econometrics, 2, 111-120.

Greene, W. H. (2008). Econometric analysis (6th ed.). Upper Saddle River: Pearson.

Kole, L., \& Meade, E. (1995). German monetary targeting: A retrospective view. Retrieved from http://www.federalreserve.gov/pubs/bulletin/

Kwitkowski, D., Phillips, P., Schumidt, P., \& Shin, Y. (1992). Testing the null hypothesis of stationarity against the alternative of a unit root. Journal of Econometrics, 54, 159-178.

Kydland, F., \& Prescott, E. (1977). Rules rather than discretion: The inconsistency of optimal plans. Journal of Political Economy, $85,473-492$.

Lutkepohl, H., Terasvirta, T., \& Wolters, J. (1999). Investigating stability and linearity of a German money demand function. Journal of Applied Econometrics, 14, 511-525.

Michell, T. (2009). What happens to economic growth when neo-classical policy replaces Keynesian? The case of South Korea., The IDS Bulletin, 13(1), 60-67.

Prescott, E. (1986). Theory ahead of business cycle measurement. Federal Reserve Bank of Minneapolis Quarterly Review, 10, 9-22.

Romer, D. (2006). Advanced macroeconomics (3rd ed.). Boston: McGraw-Hill Irwin.

Rotemberg, J. (1987). The new Keynesian microfoundations. NBER Macroeconomic Annual, 2, 69-104.

Samuelson, P. (1958). An exact consumption-Loan model of interest with or without the social contrivance of money. Journal of Political Economy, 66, 467-482.

Sarno, L. (1999). Adjustment costs and nonlinear dynamics in the money demand: Italy 1861-1991. International Journal of Finance and Economics, 4, 155-177.

Stock, J. H., \& Watson, M. W. (1988). Testing for common trends. Journal of American Statistical Association, 83, $1097-1107$. 